\title{
MicroRNA-21 dysregulates the expression of MEF2C in neurons in monkey and human SIV/HIV neurological disease
}

\author{
SV Yelamanchili ${ }^{1}$, A Datta Chaudhuri ${ }^{1}$, L-N Chen ${ }^{1}$, H Xiong ${ }^{1}$ and HS Fox ${ }^{\star, 1}$
}

\begin{abstract}
MicroRNAs (miRNAs) have important roles in regulating a plethora of physiological and pathophysiogical processes including neurodegeneration. In both human immunodeficiency virus (HIV)-associated dementia in humans and its monkey model simian immunodeficiency virus encephalitis (SIVE), we find miR-21, a miRNA largely known for its link to oncogenesis, to be significantly upregulated in the brain. In situ hybridization of the diseased brain sections revealed induction of miR-21 in neurons. miR-21 can be induced in neurons by prolonged N-methyl-D-aspartic acid receptor stimulation, an excitotoxic process active in HIV and other neurodegenerative diseases. Introduction of miR-21 into human neurons leads to pathological functional defects. Furthermore, we show that miR-21 specifically targets the mRNA of myocyte enhancer factor 2C (MEF2C), a transcription factor crucial for neuronal function, and reduces its expression. MEF2C is dramatically downregulated in neurons of HIV-associated dementia patients, as well as monkeys with SIVE. Together, this study elucidates a novel role for miR-21 in the brain, not only as a potential signature of neurological disease, but also as a crucial effector of HIV-induced neuronal dysfunction and neurodegeneration.
\end{abstract}

Cell Death and Disease (2010) 1, e77; doi:10.1038/cddis.2010.56; published online 23 September 2010

Subject Category: Neuroscience

Many facets of transcriptional and translation regulation contribute to the proper functioning of the nervous system. MicroRNAs (miRNAs) are small RNA molecules that serve as check points in transcription and translation processes. They largely function by binding to the $3^{\prime}$-UTR regions of the nascent mRNA molecules resulting in mRNA destruction or translational inhibition, thus repressing gene expression. ${ }^{1}$ miRNAs regulate a plethora of processes in the central nervous system (CNS) and have been well documented in neuronal development, neuronal plasticity and neuronal differentiation. Recognizing the role of miRNA in neuronal development and control of neuronal functional elements, it is not surprising that many researchers have sought to link miRNAs to neurodegenerative diseases. Consequently, impaired miRNA regulation has been linked to several neurological diseases including Parkinson's disease (PD), Alzheimer's disease (AD), Huntington's disease (HD) and other neurodegenerative disorders. ${ }^{2,3}$ Although $\mathrm{AD}, \mathrm{HD}$ and $\mathrm{PD}$ are sporadic and/or genetic in nature, neurodegeneration also occurs from infectious etiologies, such as in human immunodeficiency virus (HIV) infection and transmissible spongiform encephalopathies (prion diseases).

HIV-associated neurocognitive disorders (HAND), varying in severity from an asymptomatic to a mild neurocognitive impairment and in its most serious form a debilitating dementia (HIV-associated dementia, HAD), develops in a subset of individuals infected with HIV-1. ${ }^{4}$ HAND results from an indirect neurotoxicity, as HIV infects macrophages and microglia, but not neurons, in the brain. ${ }^{5,6}$ We previously identified dysregulated expression of mRNAs in the brains of monkeys with simian immunodeficiency virus (SIV) encephalitis (SIVE) and humans with HIV encephalitis (HIVE), revealing altered expression of numerous genes including those expressed in neurons. ${ }^{7,8}$ Here, we describe the differential regulation of a crucial miRNA, miRNA-21, in the brains of individuals with SIVE/HIVE and its increased expression in neurons both in the brains of diseased subjects and in vitro upon N-methyl-D-aspartic acid (NMDA) receptor stimulation. When miR-21 is expressed in human neurons, electrophysiological abnormalities result, linking its expression to neuronal dysfunction. Given the ability of miRNAs to modulate cellular mRNAs and proteins and thus cellular physiology, we identified a critical neuronal transcription factor, myocyte enhancer factor 2C (MEF2C), as a target of miR-21. In line with these results, we observe that MEF2C is downregulated at the protein level in the hippocampus and frontal cortex of SIVE/HIVE brains. These findings further underscore the importance of epigenetic changes caused by miRNA in context of neurological disease and highlights the regulatory loop, in which miRNAs function and their importance in neurodegenerative research.

\footnotetext{
${ }^{1}$ Department of Pharmacology and Experimental Neuroscience, University of Nebraska Medical Center, Omaha, NE 68198, USA

${ }^{*}$ Corresponding author: HS Fox, Department of Pharmacology and Experimental Neuroscience, University of Nebraska Medical Center, 985800 Nebraska Medical Center, DRC3008, Omaha, NE 68198-5800, USA. Tel: + 402559 4821; Fax: + 402559 7495; E-mail: hfox@unmc.edu

Keywords: HIV; neurodegeneration; MEF2C; dementia; monkey; SIV; NMDA

Abbreviations: CNS, central nervous system; HIV, human immunodeficiency virus; HIVE, HIV-encephalitis; HAD, HIV-associated dementia; HAND, HIV-associated neurocognitive disorders; Kv, voltage-gated K+; LNA, locked nucleic acid; miRNA, microRNA; MEF2C, myocyte enhancer factor 2C; MAP2, microtubule associated protein 2; NMDA, N-methyl-D-aspartic acid; SIV, simian immunodeficiency virus; SIVE, SIV encephalitis; 3'-UTR, 3'-untranslated region

Received 21.5.10; revised 06.8.10; accepted 11.8.10; Edited by A Verkhratsky
} 
Table 1 Microarray analysis of miRNA expression in control and SIVE/HIVE brains

\begin{tabular}{|c|c|c|c|c|c|c|c|c|}
\hline \multirow[b]{3}{*}{ Probe ID } & \multirow[b]{3}{*}{ Annotation } & \multicolumn{4}{|c|}{$\log _{2}$ median ratios } & & & \\
\hline & & \multicolumn{2}{|c|}{ Control } & \multicolumn{2}{|c|}{ Infected } & \multicolumn{3}{|c|}{ Infected versus control } \\
\hline & & Mean & S.D. & Mean & S.D. & $\Delta$ LMR & Fold & $t$-test \\
\hline \multicolumn{9}{|c|}{ Monkey caudate } \\
\hline 5740 & hsa-miR-21 & -1.09 & 0.25 & 0.09 & 0.62 & 1.17 & 2.26 & 0.0126 \\
\hline 10947 & hsa-miR-142-3p & -0.84 & 0.41 & 0.35 & 0.82 & 1.18 & 2.27 & 0.0411 \\
\hline 10964 & hsa-miR-155 & -0.58 & 0.23 & 0.65 & 0.46 & 1.22 & 2.34 & 0.0031 \\
\hline 10986 & hsa-miR-193a-3p & -0.80 & 0.40 & 0.28 & 0.27 & 1.08 & 2.11 & 0.0101 \\
\hline 19015 & hsa-miR-142-5p & -0.84 & 0.28 & 0.51 & 0.40 & 1.35 & 2.55 & 0.0015 \\
\hline 42550 & hsa-miR-516a-5p & -0.73 & 0.45 & 0.27 & 0.13 & 1.01 & 2.01 & 0.0053 \\
\hline \multicolumn{9}{|c|}{ Monkey hippocampus } \\
\hline 5740 & hsa-miR-21 & -0.52 & 0.32 & 0.80 & 0.43 & 1.32 & 2.50 & 0.0026 \\
\hline 10947 & hsa-miR-142-3p & -1.01 & 0.50 & 1.11 & 0.24 & 2.12 & 4.34 & 0.0003 \\
\hline 10986 & hsa-miR-193a-3p & -0.79 & 0.45 & 0.63 & 0.38 & 1.43 & 2.69 & 0.0029 \\
\hline 19015 & hsa-miR-142-5p & -0.54 & 0.36 & 1.16 & 0.27 & 1.70 & 3.24 & 0.0003 \\
\hline \multicolumn{9}{|c|}{ Human caudate } \\
\hline 5740 & hsa-miR-21 & -1.414 & 0.20 & 0.32 & 0.68 & 1.74 & 3.33 & 0.0014 \\
\hline 10947 & hsa-miR-142-3p & -1.152 & 0.20 & 0.25 & 0.89 & 1.40 & 2.63 & 0.0123 \\
\hline 10986 & hsa-miR-193a-3p & -0.613 & 0.47 & 0.46 & 0.34 & 1.08 & 2.11 & 0.0138 \\
\hline 19015 & hsa-miR-142-5p & -0.858 & 0.23 & 0.73 & 0.92 & 1.59 & 3.01 & 0.0083 \\
\hline
\end{tabular}

RNA from two regions of the monkey and one region of the human brain, as indicated, was analyzed. Shown are the mean and standard deviation (S.D.) of the log 2 median ratios for the probes corresponding to individual miRNAs. The difference in the means of the $\log _{2}$ median rations $(\Delta \mathrm{LMR})$ was calculated and the fold change determined as $2^{\Delta \mathrm{LMR}}$. Initial candidate miRNAs shown were chosen because of greater than twofold change and a $t$-test result of $P<0.05$

\section{Results}

miRNAs are significantly upregulated in SIV/HIV CNS disease. We first examined the expression of miRNAs in HIVE/SIVE human and monkey samples and control, using miRNA microarrays on a locked nucleic acid (LNA) technology-based platform. We compared miRNA expression in between diseased and control tissue from two regions of the brain known to be affected in HIV-induced CNS disease, the striatum (using the caudate nucleus) and the hippocampus. Both regions were examined in rhesus monkeys with CNS disease (SIV encephalitis), in humans with HIV encephalitis and HIV dementia only one region, the caudate, was available for analysis. In all three sets of samples, four miRNAs were significantly upregulated, based on a criterion of twofold change and $P$-value $<0.05$ (Table 1). None of the known neuron-enriched miRNAs were significantly altered. We then validated the expression change of these four miRNAs by real-time PCR on both regions of the monkey brains and in the human brain, and confirmed significant upregulation of three: miR-21, miR-142$3 p$ and miR-142-5p (Figure 1). miR-142 expression is largely confined to the hematopoietic system, whereas miR-21 expression has been found in a number of cell types and its altered expression linked to pathological changes. miR-21 was therefore chosen for further analysis.

miR-21 is induced in neurons of diseased brains. To examine the cell type in the brain responsible for the observed changes in miR-21 expression, in situ hybridization was performed on sections from uninfected and SIVE monkeys. miR-21 reactivity was minimal in uninfected monkeys (Figure 2a), and hybridization of a control scrambled miRNA probe to SIVE brains was negative
(Figure 2b). In contrast, intense reactivity for miR-21 was found in brain tissue from animals with SIVE, including cells morphologically identifiable as neurons (Figure 2c, hippocampus, and 2D, entorhinal cortex). In situ hybridization was then combined with immunostaining for the neuronspecific protein MAP2, confirming that the upregulation of miR-21 is in neurons (Figure 3).

miR-21 is upregulated by neuronal stimulation through NMDA receptors. Neuronal expression has not been reported for miR-21. In HAND, as well as other neurodegenerative conditions, including $A D, P D$ and $H D$, overstimulation of NMDA-type glutamate receptors is a likely mechanisms of neuronal injury. ${ }^{9}$ Stimulation of NMDA receptors leads to neuronal changes through cellular signaling mechanisms including alterations in gene expression. ${ }^{10,11}$ To examine whether miR-21 expression is part of the response in this pathway, we first performed a dose-response curve using a range of NMDA exposure for a prolonged time $(1 \mathrm{~h})$ and assessed miR-21 levels $24 \mathrm{~h}$ after the initial exposure in primary neurons from three different human donors. Indeed, stimulation through NMDA receptors led to a significant increase in miR-21, with a peak response at $100 \mu \mathrm{M}$ (Figure 4a). Under these conditions, there was no increase in cell death in the cultures (determined by lactate dehydrogenase release, data not shown). Repeating the experiment at $100 \mu \mathrm{M}$ NMDA in four additional independent donors confirmed the miR-21 upregulation (Figure 4b). The increased expression was not immediate, as miR-21 expression during the initial exposure to NMDA did not change (Figure 4c). Furthermore, depolarization of the neurons with $\mathrm{KCl}$ during this same time period did not induce miR-21 (Figure 4d). 

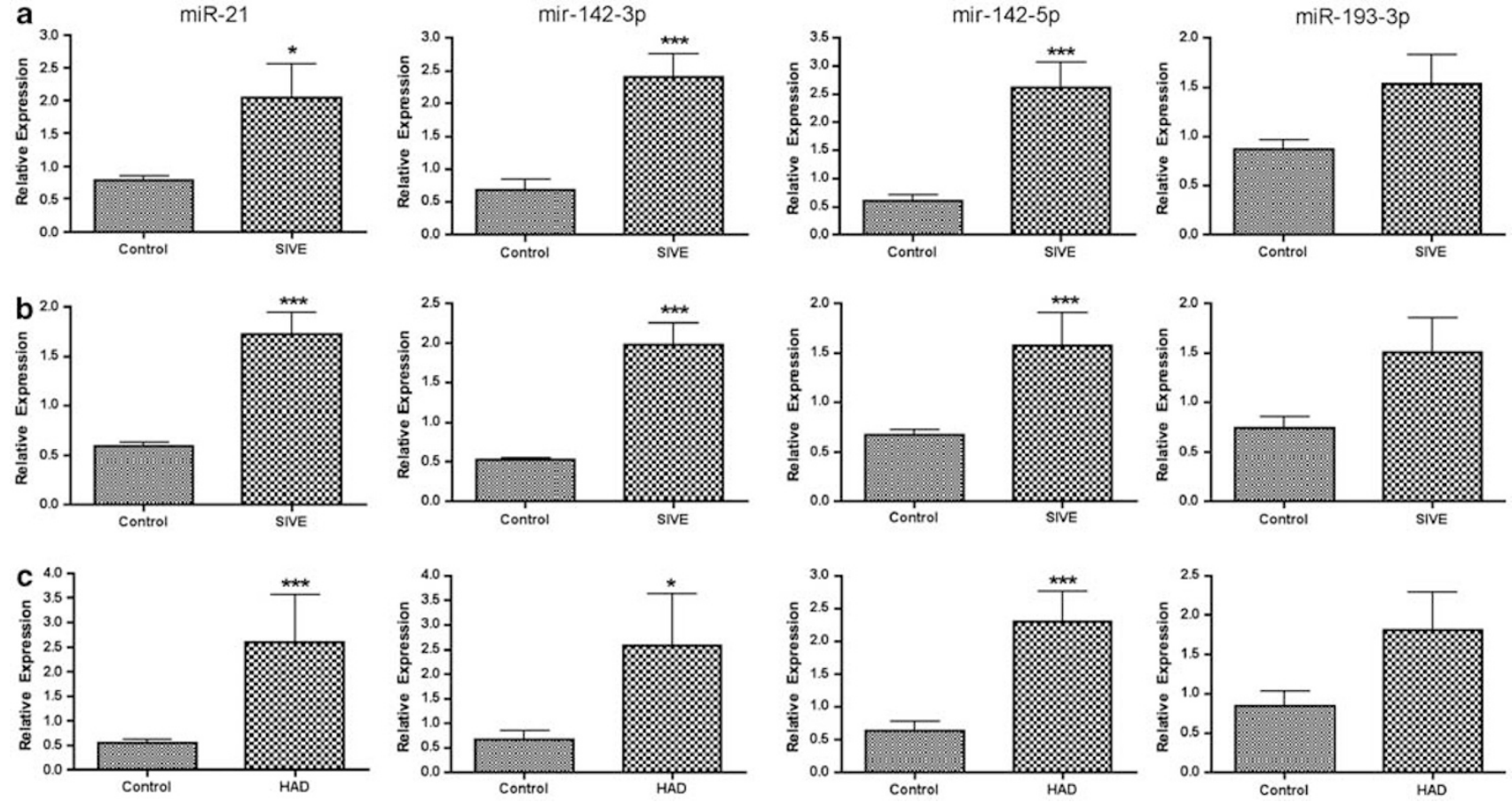

Figure 1 Altered miRNA expression in SIV/HIV infected brains. (a) Monkey caudate, (b) monkey hippocampus, (c) human caudate. Quantitative real-time PCR confirmed the upregulation of miR-21, miR-142-3p and miR-142-5p, whereas the change in miR-193-3p did not reach statistical significance. Mean and standard error of the mean shown, ${ }^{*} P<0.05,{ }^{* \star *} P<0.001$

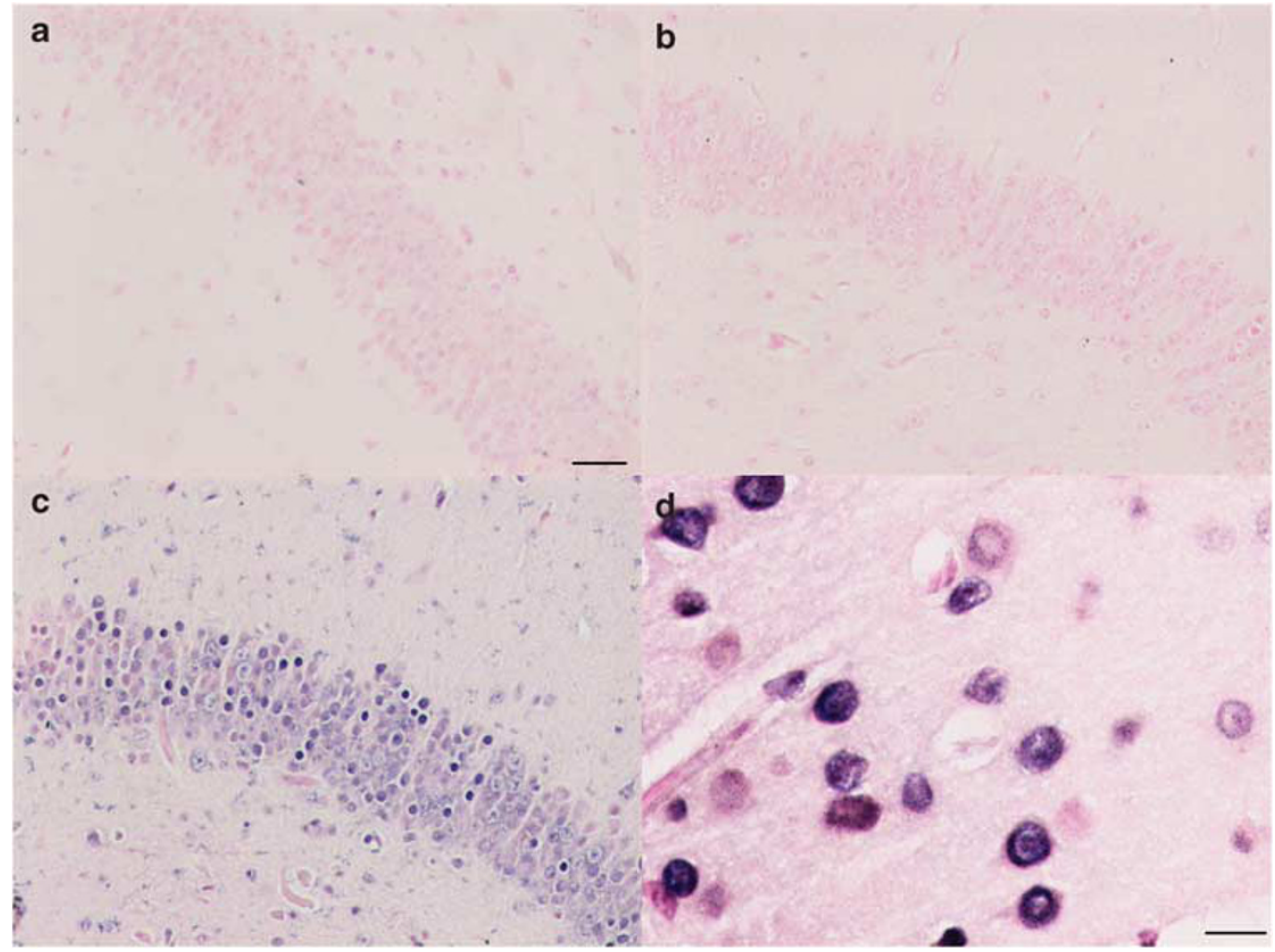

Figure 2 Photomicrographs of monkey brain tissue. In situ hybridization for miR-21 on control uninfected brains is negative (a). In brains with SIVE in situ hybridization with a scrambled probe (b) is negative, whereas miR-21 (c) is positive in neurons in the hippocampus of SIVE brains. In cortical tissue foci of neurons are positive for miR-21 (d). The brains of four control and four SIVE animals were examined. The chromagen revealing the positive reaction is blue, and nuclear fast red was used to counterstain cells. Original magnification $200 \times(\mathrm{bar}=20 \mu \mathrm{m})$ except $(\mathrm{d})$ at $630 \times(\mathrm{bar}=10 \mu \mathrm{m})$ 
a
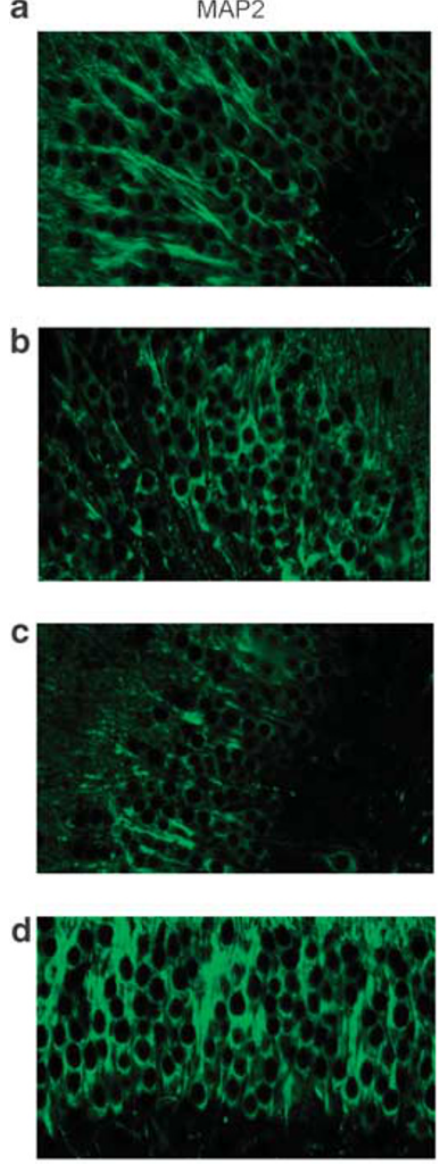

miRNA
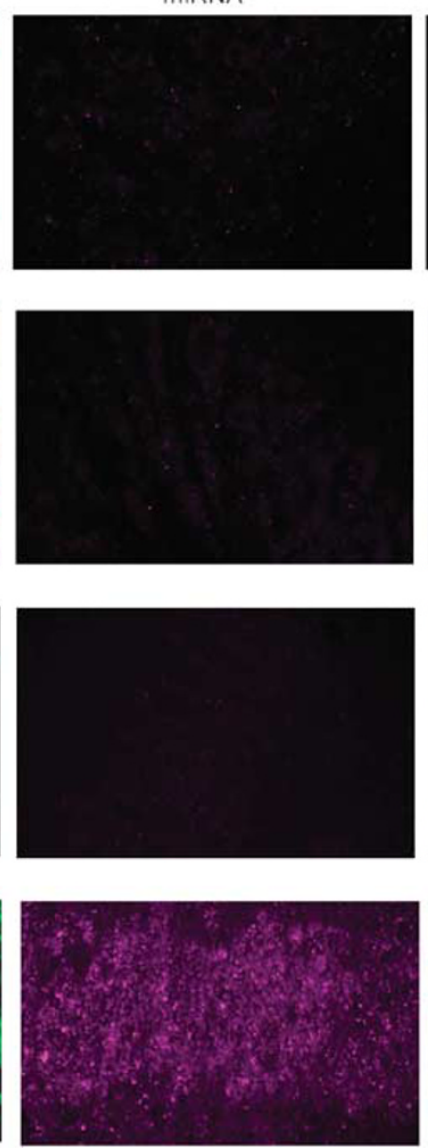

DAPI
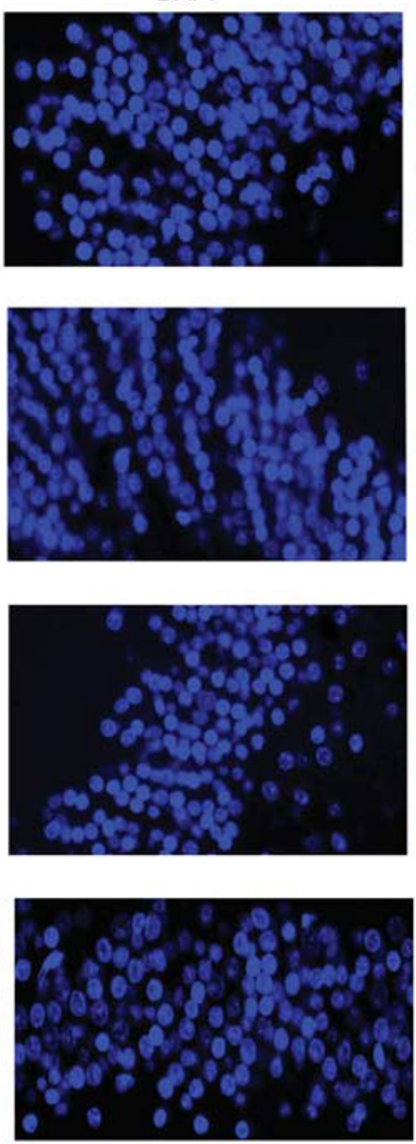

MERGE
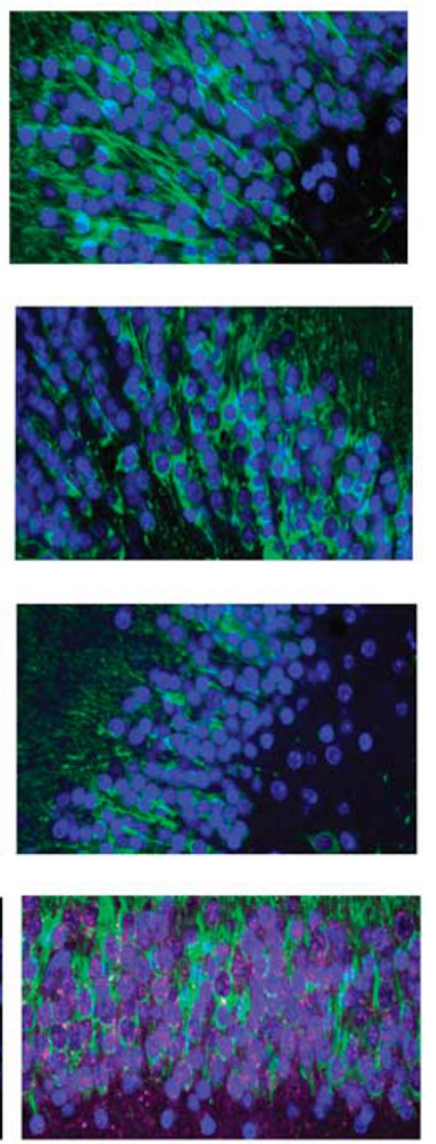

Figure 3 Combined in situ and immunostaining of monkey brain tissue. In situ hybridization for scrambled probe (a) and miR-21 (b) on control uninfected brains is negative. In brains with SIVE in situ hybridization with a scrambled probe (c) is negative, whereas miR-21 (d) is positive (pink). Anti-MAP2 staining (green) labels the neurons. Original magnification $200 \times$

miR-21 overexpression affects neuronal physiology. Although several functions of miR-21 has been reported, the majority stress its role in various types of cancer and tumors, ${ }^{12}$ and its functional significance in neurons has not been investigated. In order to assess the effects of miR-21 on neuronal function, we transduced primary human neurons with a lentivirus expressing miR-21 or a control lentivirus (Figure $5 \mathrm{a}$ and $\mathrm{b}$ ). We then performed electrophysiological analysis of voltage-gated $\mathrm{K}^{+}\left(\mathrm{K}_{\mathrm{v}}\right)$ channels, key regulators of neuronal excitability. Under whole-cell voltage clamp configuration, application of depolarizing voltage steps produced larger outward $\mathrm{K}^{+}$currents in neurons transfected with a lentivirus expressing miR-21 than the outward $\mathrm{K}^{+}$currents recorded in neurons transfected with a control lentivirus (Figure 5c). When measured at $+60 \mathrm{mV}$, the average instantaneous outward $\mathrm{K}^{+}$current density was $311.7 \pm 10.9 \mathrm{pA} / \mathrm{pF}$ in miR21-transfected neurons (mean \pm S.E.M., $n=75$ ). In contrast, the average instantaneous outward $\mathrm{K}^{+}$current density recorded in neurons transfected with viral vector alone was $263.6 \pm 11.7 \mathrm{pA} / \mathrm{pF}(n=67)$. The difference was statistically significant $(P<0.001)$, revealing that miR-21 expression in neurons produced an enhancement of the outward $\mathrm{K}^{+}$ current. These data reveal that miR-21 expression is indeed detrimental to neurons, and thus, miR-21 induction in neurons is a potential pathogenic factor in neurodegenerative disorders such as HAD and HAND.

MEF2C is a miR-21 target. With the help of target search engines, we identified MEF2C as a putative target for miR-21. MEF2C has been shown to be crucial in multiple aspects of neuronal development, function and survival, ${ }^{13-15}$ and in adult mice MEF2C is critical in learning and memory. ${ }^{16} \mathrm{We}$ therefore hypothesized that HIV-induced neurocognitive deficits could be due to repression of the MEF2C mRNA by miR-21.

To examine whether miR-21 could regulate expression via the $3^{\prime}$-UTR of the MEF2C mRNA and thereby regulating its expression, we co-transfected a luciferase reporter vector containing the MEF2C $3^{\prime}-$ UTR along with a vector expressing either miR-21, a miRNA without a target in the MEF2C $3^{\prime}$-UTR (miR-181), or a scrambled miRNA sequence in HEK293T cells. Initial experiments revealed that MEF2C $3^{\prime}$-UTR expression is repressed by miR-21, but not by a scrambled control miRNA or an irrelevant miRNA (data not shown). To assess whether this regulation is indeed because of miR-21 recognizing its predicted binding site in MEF2C rather than other nonspecific actions, we mutated the miR-21 site in 

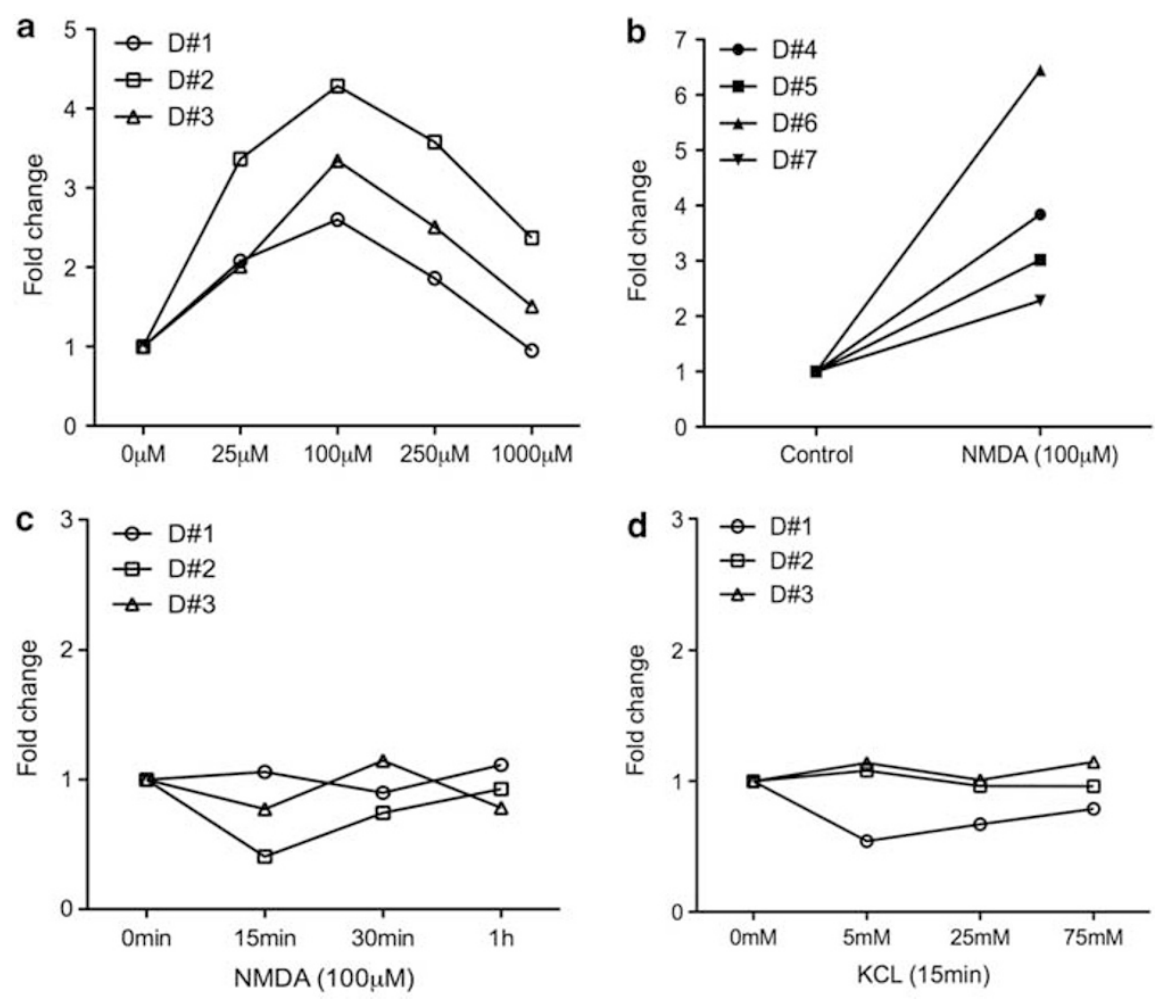

Figure 4 Regulation of miR-21 expression in human neurons. The $Y$ axes indicate the fold change, determined as $2^{-\Delta \Delta C t}$ by normalizing to baseline as 1 . (a) miR-21 expression curve for increasing concentrations of NMDA (measured $24 \mathrm{~h}$ after a $15 \mathrm{~min}$ exposure). Data are from three independent donors/experiments. Repeated measures one-way ANOVA analysis of the $\triangle \mathrm{Ct}$ values revealed a significant difference $(P<0.001)$, Tukey's post hoc test revealed significance between untreated cells and those treated with NMDA at $25 \mu \mathrm{M}(P<0.05), 100 \mu \mathrm{M}(P<0.001)$ and $250 \mu \mathrm{M}(P<0.01)$, and for those treated with $100 \mu \mathrm{M}$ NMDA compared with those at $25 \mu \mathrm{M}(P<0.05)$, $250 \mu \mathrm{M}(P<0.05)$ and $1000 \mu \mathrm{M}(P<0.01)$. (b) miR-21 expression in four additional donors at the peak $(100 \mu \mathrm{M})$ NMDA concentration. Paired $t$-test analysis of the $\Delta C$ t values revealed a significant difference $(P<0.001)$. (c) miR-21 expression as a result of short-term NMDA stimulations. No significant difference was seen. Data are from three independent donors/experiments. (d) miR-21 expression as a result of short-term $\mathrm{KCl}$ stimulation. No significant difference was seen. Data are from three independent donors/ experiments

MEF2C. Nucleotides 2-8 of the guide strand (known as the 'seed' region) are crucial determinants of the specificity of target recognition by miRNAs. As seen in Figure 6a, there is a perfect match in the seed sequence between miR-21 and complementary nucleosides in the $3^{\prime}$-UTR of the MEF2C mRNA. We then mutated the seed region in MEF2C for miR21 binding (Figure 6a) and performed the luciferase assays as above. While the wild-type MEF2C shows significant repression by miR-21, the mutant MEF2C does not (Figure 6b). As an additional control, we also tested a random genomic sequence within the luciferase vector, which showed no change upon co-transfection with miR-21.

We next transduced HEK293T cells with miR-21 and a scrambled control, and examined their effect on the endogenous MEF2C expression. Compared with the controltransduced cells, miR-21 expression decreased MEF2C expression in cells (Figure 6c). After confirming our results in HEK293T cells, we transduced human embryonic neurons. A similar effect was seen in neurons, miR-21 overexpressing neurons showed a reduction in MEF2C protein levels as compared with scrambled control (Figure 6d). Our results clearly demonstrate that MEF2C is repressed by miR-21, dependent on the seed region, and therefore is a definite target for miR-21.
MEF2C is repressed in neurons of diseased brains. MEF2C is expressed in neurons in regions that are functionally affected in HAND, including the frontal cortex and hippocampus. ${ }^{17,18}$ In order to examine whether MEF2C is altered in neurons in diseased brains we performed immunohistochemical staining on brain sections control and diseased monkey (SIVE) and human (with clinical HAD, and neuropathological HIVE) brains. While neurons from control brains show robust MEF2C immunoreactivity in neuronal nuclei (Figures 7a,b, e and f), neurons in the hippocampus and cortex from diseased monkeys and humans have a profound decrease in MEF2C protein expression (Figure7c,d, g and h).

\section{Discussion}

In this study, we report for the first time the abnormal induction of miRNA in neurons in a neurocognitive disorder, HAD/HIVE, and its animal model, SIVE. Our microarray and follow-up validation with qPCR in monkeys and humans clearly shows significant induction of miR-21. Using in situ hybridization on brain sections we have demonstrated the increase of this miRNA in neurons. 
a

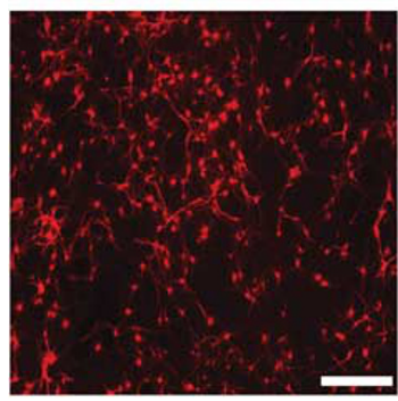

b
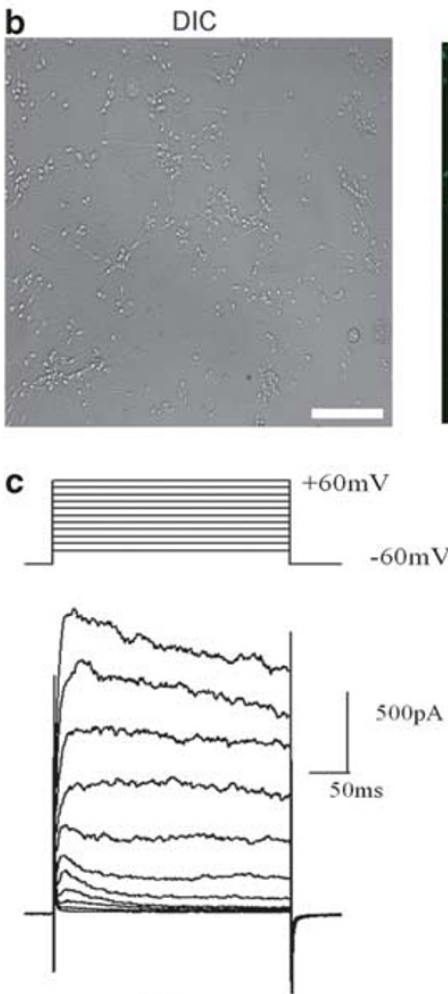

$\mathrm{Ctrl}$
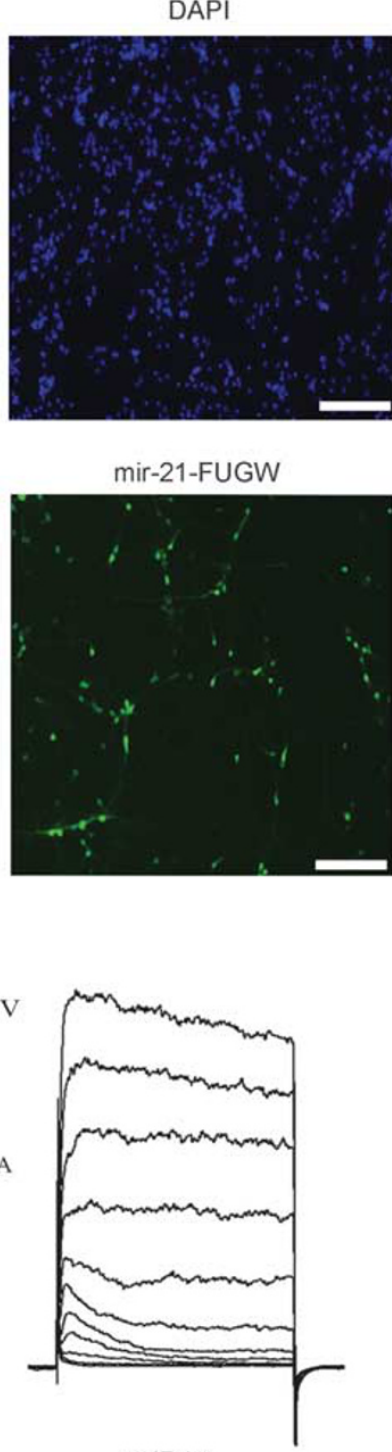

$\operatorname{miR} 21$
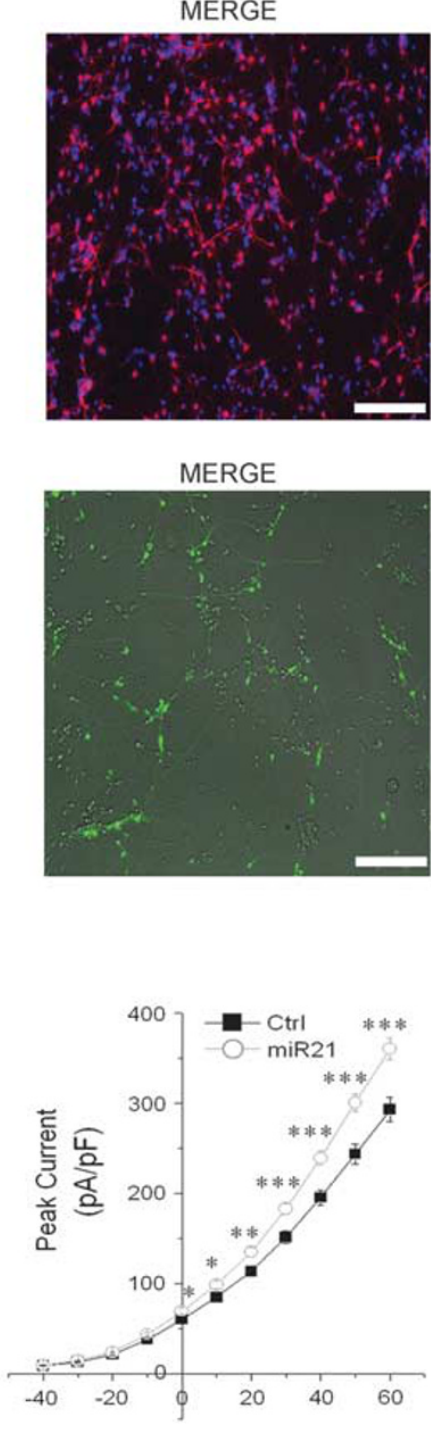

$\mathrm{mV}$

Figure 5 miR-21 alters functional properties of human neurons. (a) Representative image of human fetal brain derived neurons, stained with anti-MAP2 and DAPI. (b) Representative image of lentiviral transduced neurons, revealing the positive GFP marker in the miR-21 containing FUGW vector. (a and $\mathbf{b}-$ original magnification $100 \times$, $\mathrm{bar}=50 \mu \mathrm{m}$ ). (c) Transduction of human fetal neurons with miR-21 induced an increase of whole-cell outward $\mathrm{K}^{+}$currents generated by voltage steps shown at the top left. The representative current traces were recorded from a neuron with the control viral vector (left) and another neuron with the miR-21 viral vector (middle). Note much larger outward $\mathrm{K}^{+}$ currents were recorded from the miR-21-tranduced neuron than those recorded from the neuron transduced with vector alone. The current-voltage (I-V) relationship (right) showing the average of current densities recorded in neurons transduced with miR-21 $(n=75)$ and controls $(n=67)$, respectively, obtained from three different donors. Mean and standard error of the mean shown, significance is indicated by ${ }^{*} P<0.05$, ${ }^{\star \star} P<0.01,{ }^{\star \star \star} P<0.001$. Statistics were performed on data from three independent donors

miR-21 has been shown to be a marker for many types of cancer including brain gliomas. ${ }^{19}$ However, neuronal expression has not been previously identified. We find that stimulation of NMDA receptors leads to increased expression of miR-21 in neurons. There is precedent for increased NMDA receptor signaling to be a key component of HIV-induced CNS disease, as viral proteins such as gp120 and $\mathrm{Tat}^{20,21}$ and low molecular weight non-proteinaceous products of macrophages, ${ }^{22,23}$ the key pathogenic cells in the brain, lead to neuronal damage and death through these receptors. Given the prime role of NMDA receptors in mechanistic pathways of neurodegenerative disorders, the induction of miR-21 can represent a key event in subsequent neuronal injury.
In order to delineate the functional relevance of miR-21 upregulation in neurons, we examined specific gene targets for miR-21. While a number of targets for miR-21 have been uncovered in studies on cancer and other cell types, we focused our search on targets to neuronal genes. To our interest, we found MEF2C, a CNS transcription factor as a target gene for miR-21. While miR-21 is relatively well studied, this target has not been reported so far for miR-21. One possible reason for this is many investigators use mouse models and miRNA target prediction algorithms that rely on evolutionary conservation. While the miR-21 sequence is well conserved in mammals and other vertebrates, ${ }^{19}$ an examination of sequenced genomes reveals that the seed sequence 
a

$\{$ seed \}

5' uaaacagaaaugcugagAUAAGCUu 3' MEF2-wt |||| | | || |||||||

3' aguuguaguca-ga--cUAUUCGAu 5' hsa-miR-21 ||| | | || |||

5' uaaacagaaaugcugagAUUUCGAu 3' MEF2-mut

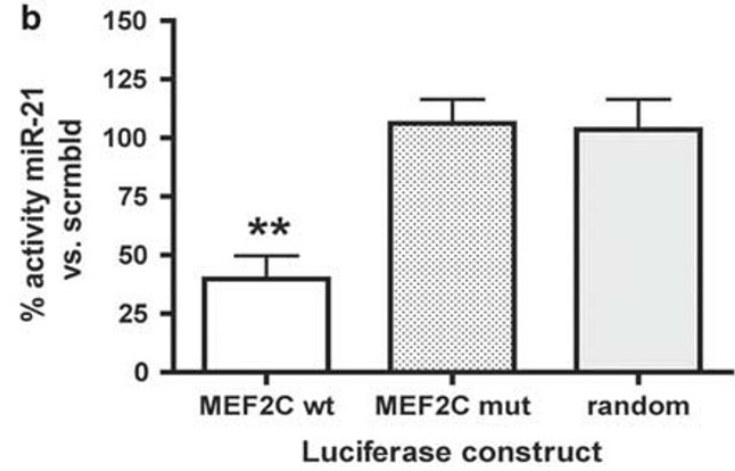

d Primary Human Neurons

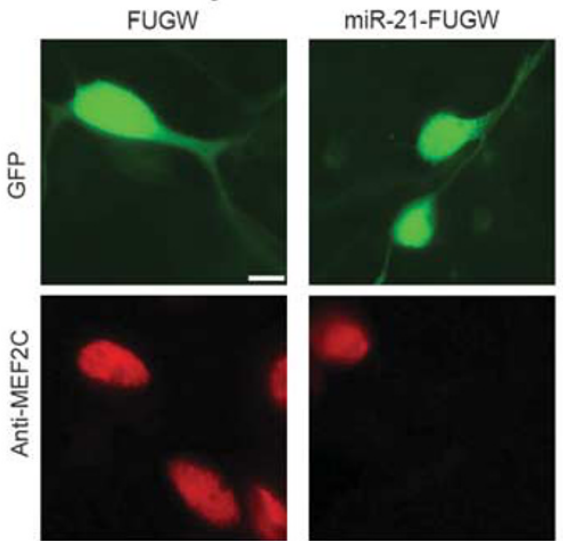

Figure 6 MEF2C is a target of miR-21. (a) Alignment and base pairing of miR-21 with the MEF2C $3^{\prime}-$ UTR. The seed region (bases 2-8) is indicated in capital letters. In vitro mutagenesis of the wild-type (wt) MEF2C sequence (upper) to alter the seed sequence and create the mutant (mut) sequence in the seed region is shown in italics (lower). (b) MiR-21 significantly lowers the activity of the wild-type MEF2C luciferase reporter, but not the mutant MEF2C or a random DNA sequence. This experiment was repeated in three independent experiments. (c) HEK293T cells or (d) human embryonic neurons were transduced with either control FUGW or miR-21-FUGW lentiviral vector. Cells were immunostained for MEF2C, as seen in the second panel, the reactivity for MEF2C decreases in miR-21 transduced cells $(630 \times$ magnification, bar $=10 \mu \mathrm{m})$. Mean and standard error of the mean shown, significance is indicated by ${ }^{* \star} P<0.01$

identified within the MEF2C mRNA is present within primates (human, chimpanzee, rhesus monkey) and many other mammals (including horse, cow, dog, rabbit, elephant, platypus), but not in mouse or rat (or opossum). In our study, as with many others on miRNAs and their targets, this target is linked to functional defects, however, we note that as each miRNA has multiple targets, the disease phenotype can be due to the combined effect of the dysregulated miRNA on numerous genes.

Our results clearly demonstrate that MEF2C is repressed by miR-21, dependent on the seed region, and therefore, is a definite target for miR-21. MEF2C has been of much interest to neuroscientists. It has been shown to be crucial for neuronal survival and its complete deficiency experimentally leads to an autism-like phenotype in mice. ${ }^{13,14}$ Other studies have found that in adult mice MEF2C is critical in learning and memory. ${ }^{16}$ While no deficits have been reported in mice carrying only one functional copy of MEF2C, in humans a number of investigators have recently reported that haploinsufficiency of MEF2C leads to severe mental retardation. ${ }^{24}$ Thus, similar to the targeting of MEF2C by miR-21, the functions of MEF2C are not fully captured in rodent models.
In order to look for functionality of miR-21 expression in neurons, we performed electrophysiological studies on neurons transfected with lentiviruses expressing miR-21. The results clearly showed that expression of miR-21 resulted in a significant enhancement of outward $\mathrm{K}^{+}$current. Such an increase is an early step in neuronal apoptosis, before commitment to cell death, ${ }^{25}$ although we did not observe neuronal death due to miR-21 expression at the time point when electrophysiological studies were performed. While the biological significance of miR-21-induced enhancement of neuronal outward $\mathrm{K}^{+}$current remains to be determined, we postulate it might reflect a part of pathogenesis of neurodegenerative disorders such as HAD. Genetic targeting studies reveal that $K_{v}$ channels have a great importance in the memory processes. ${ }^{26,27}$ Intriguingly, it has been also shown that MEF2 proteins target $\mathrm{K}_{\mathrm{v}} 1.1{ }^{28}$ We do not know as of now whether MEF2C in particular would directly target potassium channel genes, but it is a fascinating aspect to consider. Interestingly, loss of MEF2C in mice leads to increased neuronal excitatory input. ${ }^{16}$ One possibility is that an autostimulatory cycle is created, increased excitatory input through NMDA receptors leads to increased miR-21 and decreased $\mathrm{MEF} 2 \mathrm{C}$, resulting in further increased excitatory 


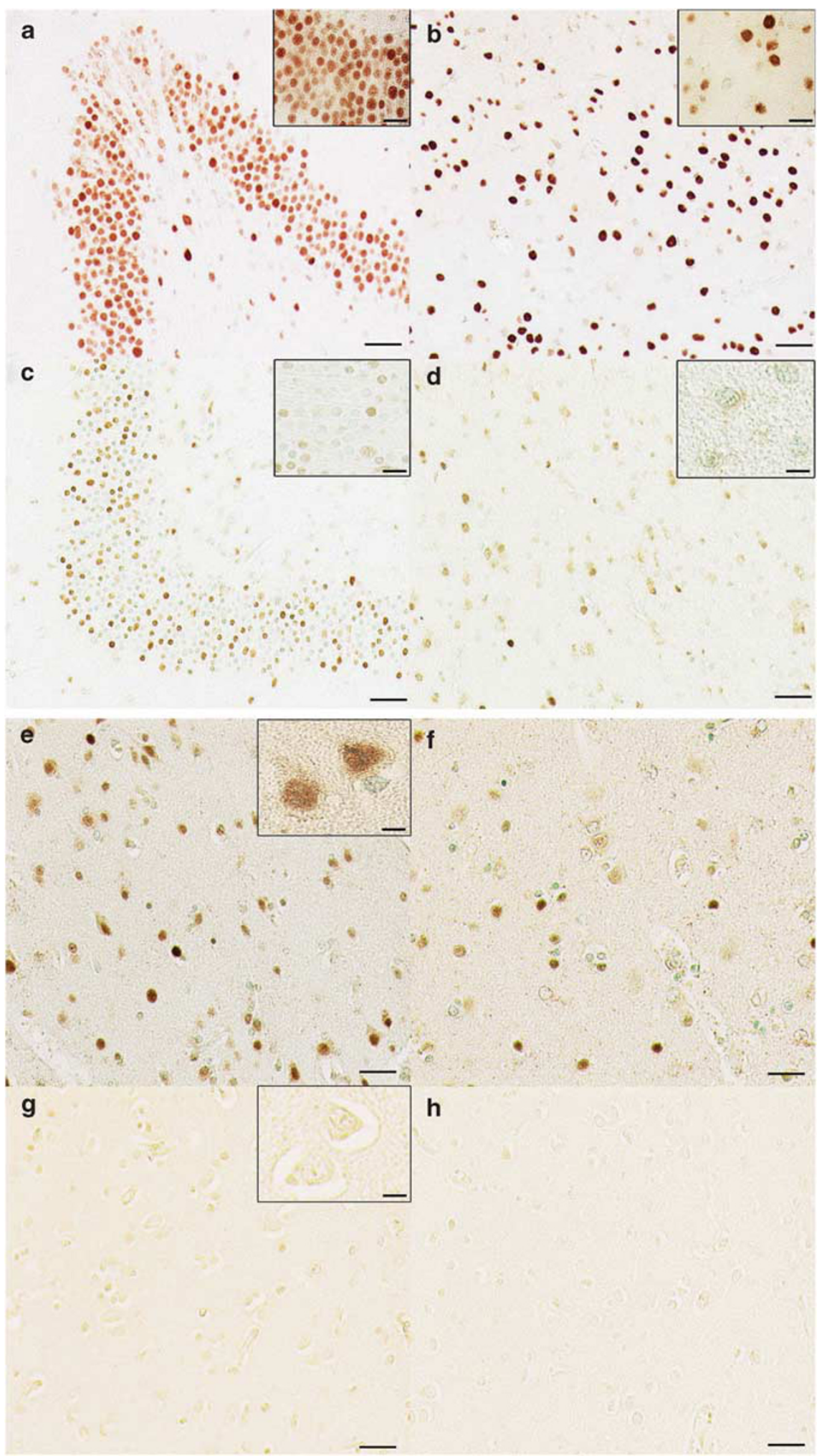

Figure 7 Photomicrographs of monkey and human brain tissue. Immunohistochemical staining for MEF2C reveals positive staining in hippocampal (a) and cortical (b) neurons of control uninfected monkeys. In monkeys with SIVE much less reactivity is seen in hippocampal (c) and cortical neurons (d). Tissue from four monkeys in each group was examined. The same result is seen in the cortex of humans, with stronger reactivity is seen in neurons in the frontal cortex of brains from individuals without HIV neurological symptoms (e and $\mathbf{f}$, representing two of the four cases examined) when compared with those with HIV-associated dementia ( $\mathbf{g}$ and $\mathbf{h}$, representing two of the three cases examined). The chromagen revealing the positive reaction is brown, and methyl green (light green) used for counterstaining. Original magnification $200 \times(\mathrm{bar}=20 \mu \mathrm{m})$ except inserts at $630 \times(\mathrm{bar}=10 \mu \mathrm{m})$ 


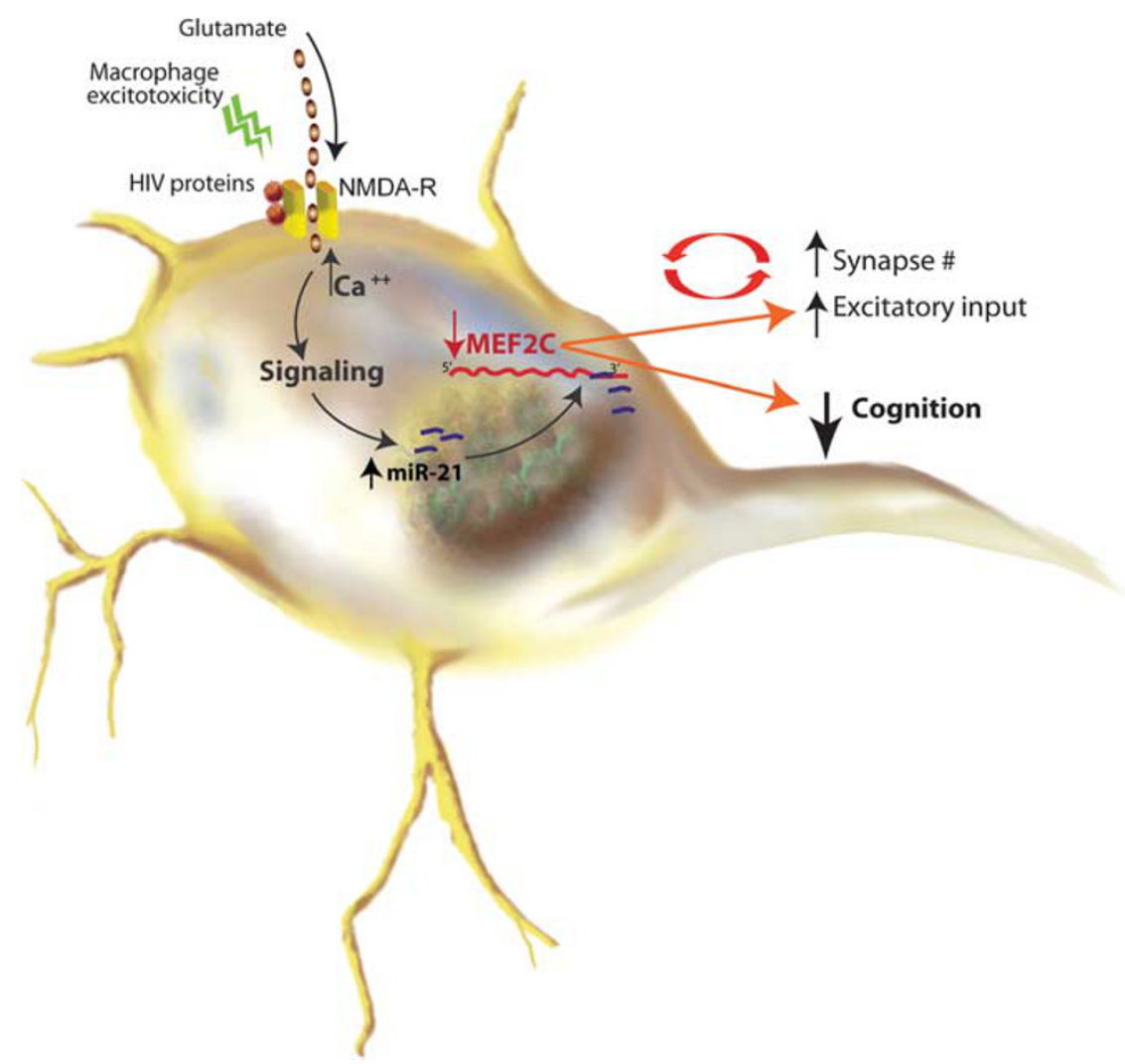

Figure 8 Model of autostimulatory neuropathogenic cycle. In CNS HIV infection, NMDA receptors (NMDA-R) can be activated through their normal ligand glutamate, as well as HIV proteins and/or excitatory molecules from macrophages. This increased excitatory input results in induction of miR-21 that decreases MEF2C, resulting in further increased excitatory input. This neuronal damage, along with alterations in the other neuronal functions involving MEF2C, results in cognitive dysfunction

input, which maintains or further increases miR-21 and decreases MEF2C (Figure 8). Such a cycle would result in neuronal dysfunction and possibly excitotoxic death.

miRNA expression in frontal cortical gray matter miRNAs was examined in another study looking at the effect of depression in HIV infected individuals, but miR-21 was not identified as having this association. ${ }^{29}$ In addition, similar to our studies with NMDA treatment of human neurons, the HIV protein Tat was used to treat rodent neurons, revealing the upregulation of miR-128a but not miR-21. ${ }^{30}$ However, there are significant interspecies differences between rodent and human neurons in response to Tat, ${ }^{31}$ and such studies would need to be repeated with human neurons. Thus, it is possible that in addition to NMDA, viral proteins as well as other molecules implicated in the neuropathogenesis of HIV could result in alterations of miR-21 in human neurons (Figure 8). Interestingly, another recently reported study examined miRNAs in subcortical white matter in HIVE, and found a number of up- and down-regulated molecules. ${ }^{32}$ In that study, downregulation of miRNAs was linked to increased caspase- 6 in astrocytes and astrocyte injury. miR-21 was not identified, likely because of the examination of white matter versus the neuron-rich regions studied here. Infiltration and activation of macrophages in the brain is a well-characterized neuropathological component of SIVE/HIVE. While miRNAs have also been studied in macrophages in relationship to HIV infection and interferon production, ${ }^{33,34}$ changes in miR-21 or others miRNAs in macrophages in CNS disease have not yet been reported.

Our data provides compelling evidence that MEF2C is an important target for miR-21 in neurons. miR-21 induction, through repression of MEF2C and potentially other genes, could lead to deficits in neurocognitive functions as seen in HIV infection and possibly other disorders. These studies also reveal additional reasons why rodent systems may not be optimal for the study of certain neurodegenerative conditions. ${ }^{35}$ Our study in humans and nonhuman primates thereby provides a unique mechanism of disease: neuronal induction of miRNAs in a setting of CNS infection, revealing a novel mechanism of dysregulation of CNS function and providing new avenues in brain research.

\section{Materials and Methods}

Ethics statement. The monkey samples were from rhesus macaques used in our previous studies on SIV pathogenesis ${ }^{36,37}$ that were performed under IACUC approval from The Scripps Research Institute. Human RNA samples were obtained from the National NeuroAIDS Tissue Consortium (NNTC) (http://www.nntc.org), operating under IRB approval from the participating institutions (University of California San Diego, University of California Los Angeles, University of Texas Medical Branch at Galveston, and Mt. Sinai Medical Center in New York). Fetal brain tissue for primary neuronal culture was obtained in full compliance with the ethical guidelines of the NIH and under IRB approval from the University of Washington and the University of Nebraska Medical Center. 
miRNA microarray studies. Total cellular RNA was isolated from frozen $\left(-80^{\circ} \mathrm{C}\right)$ brain specimens by using TRIzol (Invitrogen, Carlsbad, CA, USA) for the monkey samples, and RNAzol (Biotecx Laboratories, Houston, TX, USA) for the human samples, followed by column purification (miRNeasy, Qiagen, Valencia, CA, USA) as per manufacture's instructions. For the monkeys, four samples were from uninfected animals and four from SIV-infected animals that developed simian AIDS with SIV encephalitis. For the human samples, six samples were from individuals who were HIV negative with no history of dementia or neurocognitive disability and showed no significant neuropathology. Five samples were from HIV positive individuals that were neurocognitively impaired (NNTC clinical rating $>6$ ) ${ }^{38}$ and a neuropathological diagnosis of HIV encephalitis. Clinical information is provided in the supplemental material. For microarray analysis, only three of the HAD specimens were sufficient for use, but all five were used for the qRT-PCR studies.

miRNA microarray analysis was performed by using the miRCURY LNA microarray (version 11.0) microRNA at Exiqon S/A (Vedbaek, Denmark). The microarray data have been deposited in NCBI's gene expression omnibus and are accessible through GEO (http://www.ncbi.nlm.nih.gov/geo/query/acc.cgi?).

miRNA quantitative real-time PCR (qRT-PCR). For the brain RNA samples, qRT-PCR was performed on the same samples used for microarray analysis above at Exiqon. Endogenous controls were chosen based on their relative stability on the microarrays, and the three best endogenous controls (let-7e, let-7C, and miR-423-3p) were used for normalizing the quantified signal of the miRNAs. For the primary human neuronal culture RNA samples, Taqman qRT-PCR assays for hsa-miR-21 and U6 snRNA for endogenous control were purchased and performed as per manufacturer's instructions from ( $\mathrm{ABI}, \mathrm{Carlsbad}, \mathrm{CA}, \mathrm{USA})$.

The relative expressions were calculated based on the efficiency corrected $\mathrm{Ct}$ method; the PCR efficiency was estimated from a serial dilution of CDNA generated from pooled RNA of the samples. Data (in $\log _{2}$ format) were exported into Excel (Microsoft, Redmond, WA, USA) and analyzed for differential expression by using the two-tailed Student's t-test (for two-group comparisons) or into Prism (GraphPad Software, San Diego, CA, USA) for one-way ANOVA followed by post hoc testing (for multiple group comparisons).

miRNA in situ hybridization. Following necropsy, monkey caudate and hippocampus were formalin fixed, and embedded in paraffin, and $5 \mu \mathrm{m}$ sections cut onto glass slides. The in situ hybridization was performed at Phylogeny Inc. (Columbus, OH, USA) as described previously. ${ }^{39}$ Monkey spleen was used as a positive control. At least two hybridizations were done for each probe on each brain section.

Combined in situ hybridization and immunofluorescence. We adapted our protocol for radiolabelled in situ hybridization and colorimetric immunohistochemisty ${ }^{7}$ to fluorescence as follows. Following deparaffinization and antigen retrieval with citrate, sections were pre-hybridized in hybridization buffer (50\% formamide, $10 \mathrm{mM}$ Tris- $\mathrm{HCl}$, pH 8.0, $200 \mu \mathrm{g} / \mathrm{ml}$ yeast tRNA, $1 \times$ Denhardt's solution, $600 \mathrm{mM} \mathrm{NaCl}, 0.25 \%$ SDS, $1 \mathrm{mM}$ EDTA, $10 \%$ dextran sulfate) for $1 \mathrm{~h}$ at $37^{\circ} \mathrm{C}$ in a humidified chamber. LNA modified miR-21 and scrambled miR probes, labeled at both the $5^{\prime}$ and $3^{\prime}$ ends with digoxigenin (Exiqon), were diluted to final concentration of $2 \mathrm{pM}$ in hybridization buffer, heated to $65^{\circ} \mathrm{C}$ for $5 \mathrm{~min}$, and separately hybridized to the sections at $37^{\circ} \mathrm{C}$ overnight. The slides were then washed twice in hybridization buffer (without probe) at $37^{\circ} \mathrm{C}$, followed by washing three times in $2 \times \mathrm{SSC}$ and twice in $0.2 \times \mathrm{SSC}$ at $42^{\circ} \mathrm{C}$. They were then blocked with $1 \% \mathrm{BSA}, 3 \%$ normal goat serum in $1 \times$ PBS for $1 \mathrm{~h}$ at room temperature and incubated with anti-digoxigenin conjugated with horseradish peroxidase $1: 100$, Roche Diagnostics GmbH, Mannheim, Germany) and anti-MAP2 (1:1500, Sternberger Monoclonals Inc., Baltimore, MD, USA) antibodies overnight at $4^{\circ} \mathrm{C}$. The slides were washed twice with PBS and incubated with Alexa Fluor 568 goat anti-mouse IgG (1:400, Invitrogen) antibody for $1 \mathrm{~h}$ at room temperature. This was followed by two PBS washes and signal amplification (for the in situ, now labeled with horseradish peroxidae) using TSA Cy5 kit (PerkinElmer, Waltham, MA, USA) according to the manufacturer's protocol. The slides were mounted in Prolong gold anti-fade reagent with DAPI (Invitrogen).

Isolation, cultivation and treatments of human neurons. Fetal brain tissue (first/second trimester) was obtained from the Birth Defects Laboratory, University of Washington, Seattle, WA, USA. Neuronal cultures were prepared by incubating dissociated tissue with $0.25 \%$ trypsin for 30 min, neutralized with $10 \%$ fetal bovine serum, and further dissociating by triturating. The resulting single cell suspension was cultured on poly-D-lysine-coated plates in neurobasal media containing $0.5 \mathrm{mM} \mathrm{l-glutamine,} 50 \mu \mathrm{g} / \mathrm{ml}$ penicillin and streptomycin and supplemented with B27 (Invitrogen). Matured neurons were stained with a neuronal-specific MAP2 antibody (Calbiochem, San Diego, CA, USA) to confirm the purity.

For NMDA and KCL treatments, neurons were grown to 15 days in vitro (DIV) and cultures were then treated with the indicated concentrations of NMDA and $10 \mu \mathrm{M}$ glycine. After $1 \mathrm{~h}$ treatment, cultures were replaced with normal neuronal medium. After $24 \mathrm{~h}$, the neurons were collected in TRIzol and RNA was extracted for analysis. For KCL stimulation, treatment was carried out for $15 \mathrm{~min}$ at the indicated concentrations before the extraction of RNA.

For lentivirus transduction, neurons were transduced with miR-21 or control lentivirus at a biological titer of $1 \times 10^{10}$ transduction units $/ \mathrm{ml}$ at $7 \mathrm{DIV}$. Neurons were cultured for another 4 days after transduction, used for MEF2C immunofluorescence or electrophysiology, which was performed on GFP positive cells.

miR-21 expressing lentivirus. We generated a miR-21 lentiviral vector by subcloning the precursor miR-21 fragment into the Pac1/Nhe1 cloning sites of the FUGW, a self inactivating, replication incompetent lentiviral vector that carries the human ubiquitin-C promoter driving a GFP reporter gene. Human embryonic kidney 293 T cells were transfected by using Fugene 6 (Roche Applied Science, Indianapolis, IN, USA) with the expression vector and two helper plasmids, $\Delta 8.9$ and vesicular stomatitis virus $G$ protein. Virions were isolated by ultracentrifugation of filtered supernatant. For the control virus, the vector without the miR-21 insert was used.

Electrophysiology. Whole-cell voltage-clamp recordings were performed on transduced (GFP-positive) primary human neuronal cultures (from three donors) in $35 \mathrm{~mm}$ tissue culture dishes on the stage of an inverted Nikon microscope (TE 300) using an Axonpatch 200B amplifier (Molecular Devices, Sunnyvale, CA, USA). Patch electrodes, made from borosilicate glass micropipettes (WPI Inc., Sarasota, FL, USA) with a P-97 micropipette puller (Sutter Instruments, Novato, CA, USA), had tip resistance of 5.0-8.0 M $\Omega$. The electrodes were advanced toward cells by a Burleigh micromanipulator (PC-5000, EXFO, Mississauga, ON, Canada). After establishment of the whole-cell patch configuration, the cells were allowed to stabilize for 3-5 min before tests. The recorded cells were held at $-60 \mathrm{mV}$ during voltage clamping. Whole-cell outward $\mathrm{K}^{+}$currents were induced by applying depolarizing voltage steps $(300 \mathrm{~ms}$ in duration) from the holding potential of $-60 \mathrm{mV}$ to $-40 \mathrm{mV}$ in the first step, and then stepped to $+60 \mathrm{mV}$ in increments of $10 \mathrm{mV}$. Junction potentials were corrected, and the cell capacitance was uncompensated. Current signals were filtered at $1 \mathrm{kHz}$ and digitized at $5 \mathrm{kHz}$ using Digidata 1440A digitizer (Molecular Devices). The current and voltage traces were displayed and recorded in a Dell computer using PCLAMP 10.2 data acquisition/analysis system (Molecular Devices).

The pipette and extracellular solutions for voltage-clamp experiments were as described by Sodickson et al. ${ }^{40}$ In order to block voltage-gated sodium channels, $1.0 \mu \mathrm{M}$ tetrodotoxin (Tocris Bioscience, Ellisville, MO, USA) was added to the extracellular solution. All experiments were done at room temperature $\left(22-23^{\circ} \mathrm{C}\right)$. Data was analyzed using Clampfit 10.2 software (Molecular Devices). For I-V curves, the current densities of the instantaneous outward K + currents, generated by voltage steps, were measured and analyzed in each group. Student's $t$-test (twotailed) was employed for statistical analyses.

3'-UTR analysis for miRNA regulation. The MEF2C $3^{\prime}$-UTR luciferase reporter vector was purchased from Switchgear Genomics (Menlo Park, CA, USA), and the precursor miRNA containing vectors from Cellbiolabs (San Diego, CA, USA). Site-directed mutagenesis was performed using the QuickChange Lightning kit (Stratagene, La Jolla, CA, USA). To test suppression by miRNA, the miRNA of interest was co-transfected into HEK293T cells with the indicated $3^{\prime}$-UTR luciferase reporter and with Renilla luciferase (pRL-TK Vector, Promega, Madison, WI, USA) as a transfection efficiency control. The luciferase signal was measured with DuoGlo luciferase assay kit (Promega). The normalized data (the signal from the $3^{\prime}$-UTR firefly luciferase to the control Renilla luciferase) were imported into Prism (GraphPad Software) and analyzed by one-way ANOVA. When the ANOVA $P$-value was $<0.05$ the Newman-Kuels multiple comparison test was used to assess group differences. 
MEF2C immunostaining. A rabbit monospecific anti-MEF2C antibody (Human Protein Atlas antibody ID\# HPA005533 from the Human Proteome Resource program, distributed by Sigma, St. Louis, MO, USA) was used for all studies. Immunofluorescence was performed on cells transduced with GFP. expressing lentiviral control and miR-21 constructs. An Alexaflour 488 goat-anti rabbit secondary antibody (Invitrogen) was used for detection followed by mounting with Prolong gold antifade reagent containing DAPI (Invitrogen).

Immunohistochemistry was performed on 5-6 $\mu \mathrm{m}$ formalin-fixed, paraffinembedded tissue blocks from the monkey hippocampus and human frontal cortex. Antigen retrieval was performed by heating in citrate buffer. For detection, SuperPicture broad spectrum secondary antibody-horseradish peroxidase polymer reagent (Invitrogen) was used followed by chromogenic development with $3,3^{\prime}$. diaminobenzidine and a methyl-green counterstain.

\section{Conflicts of Interest}

Drs. HS Fox and H Xiong are supported by grants from the US National Institutes of Health. All the other authors declare no financial conflicts of interest.

Acknowledgements. This is paper 05 from the UNMC CITN. We thank Brenda Morsey, James Beuscher, Katie Emanuel and Ben Lamberty for outstanding assistance, and members of the Fox Lab, our department, and Dr. Avindra Nath (Johns Hopkins University) for helpful comments and suggestions.

1. Makeyev EV, Maniatis T. Multilevel regulation of gene expression by microRNAs. Science 2008; 319: 1789-1790.

2. Hebert SS, De Strooper B. Alterations of the microRNA network cause neurodegenerative disease. Trends Neurosci 2009; 32: 199-206.

3. Yelamanchili SV, Fox HS. Defining larger roles for 'tiny' RNA molecules: role of miRNAs in neurodegeneration research. J Neuroimmune Pharmacol 2010; 5: 63-69.

4. Antinori A, Arendt G, Becker JT, Brew BJ, Byrd DA, Cherner M et al. Updated research nosology for HIV-associated neurocognitive disorders. Neurology 2007; 69: 1789-1799.

5. Kaul M, Garden GA, Lipton SA. Pathways to neuronal injury and apoptosis in HIV-associated dementia. Nature 2001; 410: 988-994.

6. Kraft-Terry SD, Buch SJ, Fox HS, Gendelman HE. A coat of many colors: neuroimmune crosstalk in human immunodeficiency virus infection. Neuron 2009; 64: 133-145.

7. Roberts ES, Zandonatti MA, Watry DD, Madden LJ, Henriksen SJ, Taffe MA et al Induction of pathogenic sets of genes in macrophages and neurons in neuroAIDS Am J Pathol 2003; 162: 2041-2057.

8. Masliah E, Roberts ES, Langford D, Everall I, Crews L, Adame A et al. Patterns of gene dysregulation in the frontal cortex of patients with HIV encephalitis. J Neuroimmunol 2004; 157: 163-175.

9. Lipton SA, Rosenberg PA. Excitatory amino acids as a final common pathway for neurologic disorders. N Engl J Med 1994; 330: 613-622.

10. Xia Z, Dudek H, Miranti CK, Greenberg ME. Calcium influx via the NMDA receptor induces immediate early gene transcription by a MAP kinase/ERK-dependent mechanism. J Neurosci 1996; 16: 5425-5436.

11. Zhang SJ, Steijaert MN, Lau D, Schutz G, Delucinge-Vivier C, Descombes $P$ et al. Decoding NMDA receptor signaling: identification of genomic programs specifying neuronal survival and death. Neuron 2007; 53: 549-562.

12. Krichevsky AM, Gabriely G. miR-21: a small multi-faceted RNA. J Cell Mol Med 2009; 13 39-53.

13. Li H, Radford JC, Ragusa MJ, Shea KL, McKercher SR, Zaremba JD et al. Transcription factor MEF2C influences neural stem/progenitor cell differentiation and maturation in vivo. Proc Natl Acad Sci USA 2008; 105: 9397-9402.

14. Li Z, McKercher SR, Cui J, Nie Z, Soussou W, Roberts AJ et al. Myocyte enhancer factor $2 \mathrm{C}$ as a neurogenic and antiapoptotic transcription factor in murine embryonic stem cells. $J$ Neurosci 2008; 28: 6557-6568.

15. Tang X, Wang X, Gong X, Tong M, Park D, Xia Z et al. Cyclin-dependent kinase 5 mediates neurotoxin-induced degradation of the transcription factor myocyte enhancer factor 2 . $J$ Neurosci 2005; 25: 4823-4834

16. Barbosa AC, Kim MS, Ertunc M, Adachi M, Nelson ED, McAnally J et al. MEF2C, a transcription factor that facilitates learning and memory by negative regulation of synapse numbers and function. Proc Natl Acad Sci USA 2008; 105: 9391-9396.

17. Leifer D, Golden J, Kowall NW. Myocyte-specific enhancer binding factor $2 \mathrm{C}$ expression in human brain development. Neuroscience 1994; 63: 1067-1079.
18. Lyons GE, Micales BK, Schwarz J, Martin JF, Olson EN. Expression of mef2 genes in the mouse central nervous system suggests a role in neuronal maturation. J Neurosci 1995; 15: $5727-5738$.

19. Selcuklu SD, Donoghue MT, Spillane C. miR-21 as a key regulator of oncogenic processes. Biochem Soc Trans 2009; 37: 918-925

20. Lipton SA, Sucher NJ, Kaiser PK, Dreyer EB. Synergistic effects of HIV coat protein and NMDA receptor-mediated neurotoxicity. Neuron 1991; 7: 111-118.

21. Nath A, Psooy K, Martin C, Knudsen B, Magnuson DS, Haughey N et al. Identification of a human immunodeficiency virus type 1 Tat epitope that is neuroexcitatory and neurotoxic. J Virol 1996; 70: 1475-1480.

22. Giulian D, Yu J, Li X, Tom D, Li J, Wendt E et al. Study of receptor-mediated neurotoxins released by HIV-1-infected mononuclear phagocytes found in human brain. J Neurosci 1996; 16: 3139-3153

23. O'Donnell LA, Agrawal A, Jordan-Sciutto KL, Dichter MA, Lynch DR, Kolson DL. Human immunodeficiency virus (HIV)-induced neurotoxicity: roles for the NMDA receptor subtypes. J Neurosci 2006; 26: 981-990.

24. Le Meur N, Holder-Espinasse M, Jaillard S, Goldenberg A, Joriot S, Amati-Bonneau P et al. MEF2C haploinsufficiency caused by either microdeletion of the $5 q 14.3$ region or mutation is responsible for severe mental retardation with stereotypic movements, epilepsy and/or cerebral malformations. J Med Genet 2010; 47: 22-29.

25. Yu SP, Yeh CH, Sensi SL, Gwag BJ, Canzoniero LM, Farhangrazi ZS et al. Mediation of neuronal apoptosis by enhancement of outward potassium current. Science 1997; 278: 114-117.

26. Giese KP, Peters M, Vernon J. Modulation of excitability as a learning and memory mechanism: a molecular genetic perspective. Physiol Behav 2001; 73: 803-810.

27. Giese KP, Storm JF, Reuter D, Fedorov NB, Shao LR, Leicher T et al. Reduced K+ channel inactivation, spike broadening, and after-hyperpolarization in Kvbeta1.1-deficient mice with impaired learning. Learn Mem 1998; 5: 257-273.

28. Flavell SW, Kim TK, Gray JM, Harmin DA, Hemberg M, Hong EJ et al. Genome-wide analysis of MEF2 transcriptional program reveals synaptic target genes and neuronal activity-dependent polyadenylation site selection. Neuron 2008; 60: 1022-1038.

29. Tatro ET, Scott ER, Nguyen TB, Salaria S, Banerjee S, Moore DJ et al. Evidence for Alteration of Gene Regulatory Networks through MicroRNAs of the HIV-infected brain: novel analysis of retrospective cases. PLOS ONE 2010; 5: e10337.

30. Eletto D, Russo G, Passiatore G, Del Valle L, Giordano A, Khalili K et al. Inhibition of SNAP25 expression by HIV-1 Tat involves the activity of mir-128a. J Cell Physiol 2008; 216: $764-770$.

31. Eugenin EA, King JE, Hazleton JE, Major EO, Bennett MV, Zukin RS et al. Differences in NMDA Receptor Expression During Human Development Determine the Response of Neurons to HIV-Tat-mediated Neurotoxicity. Neurotox Res, e-pub ahead of print 22 January 2010, PMID: 20094923.

32. Noorbakhsh F, Ramachandran R, Barsby N, Ellestad KK, LeBlanc A, Dickie P et al. MicroRNA profiling reveals new aspects of HIV neurodegeneration: caspase- 6 regulates astrocyte survival. FASEB J 2010; 24: 1799-1812.

33. Luers AJ, Loudig OD, Berman JW. MicroRNAs are expressed and processed by human primary macrophages. Cell Immunol 2010; 263: 1-8.

34. Witwer KW, Sisk JM, Gama L, Clements JE. MicroRNA regulation of IFN-beta protein expression: rapid and sensitive modulation of the innate immune response. $J$ Immunol 2010; 184: 2369-2376.

35. Martin B, Ji S, Maudsley S, Mattson MP. 'Control' laboratory rodents are metabolically morbid: why it matters. Proc Natl Acad Sci USA 2010; 107: 6127-6133.

36. Burdo TH, Marcondes MC, Lanigan CM, Penedo MC, Fox HS. Susceptibility of Chinese rhesus monkeys to SIV infection. AIDS (London, England) 2005; 19 : 1704-1706.

37. Huitron-Resendiz S, Marcondes MC, Flynn CT, Lanigan CM, Fox HS. Effects of simian immunodeficiency virus on the circadian rhythms of body temperature and gross locomotor activity. Proc Natl Acad Sci USA 2007; 104: 15138-15143.

38. Woods SP, Rippeth JD, Frol AB, Levy JK, Ryan E, Soukup VM et al. Interrater reliability of clinical ratings and neurocognitive diagnoses in HIV. J Clin Exp Neuropsychol 2004; 26: 759-778.

39. Nuovo G. In situ detection of precursor and mature microRNAs in paraffin embedded, formalin fixed tissues and cell preparations. Methods 2008; 44: 39-46.

40. Sodickson DL, Bean BP. GABAB receptor-activated inwardly rectifying potassium current in dissociated hippocampal CA3 neurons. J Neurosci 1996; 16: 6374-6385.

Cell Death and Disease is an open-access journal published by Nature Publishing Group. This work is licensed under the Creative Commons Attribution-Noncommercial-Share Alike 3.0 Unported License. To view a copy of this license, visit http:// creativecommons.org/licenses/by-nc-sa/3.0/ 